\title{
Uptake in Task-elicited L2 Performance: Can Task Complexity Matter?
}

\author{
Massoud Yaghoubi-Notash \\ English Department, Faculty of Persian Literature \& Foreign Languages, University of Tabriz, Tabriz, Iran \\ Email: masoud.yaghoubi@gmail.com \\ Mohammad Hossein Yousefi \\ Peyame-Noor University, Miandoab Branch, Miandoab, Iran \\ Email: mhh.yousefi@gmail.com
}

\begin{abstract}
Concern with interaction seems to underlie a tendency to concentrate on learner and their production. Uptake, as a student initiated interaction in response to task, typically highlights the role of taskelicited interaction on the learners' part. This phenomenon is argued to lead to noticing salient features in L2 and fluency enhancement. What is, however, ignored is whether complexity of the eliciting task plays any role in the rate and frequency of uptake. This research focused on 60 Iranian students in teacher-initiated FFEE (focus on form episodes). Chi-square results indicated that task complexity could not determine the rate of uptake, but within the scope of the uptakes that occurred the successful ones were significantly due to task complexity. Results and implications are discussed.
\end{abstract}

Index Terms - uptake, task, task complexity

\section{INTRODUCTION}

Some of the most recent trends in SLA research have addressed the issue of acquisition from an interactional perspective. Mainly rooted in cognitive approaches to language acquisition, these trends lay emphasis on how learners linguistically perform in fulfilling L2 communication requirements relying on their stock of internalized language. A typical issue of interest for researchers and practitioners, informed by these approaches, is the notion of learner 'uptake' (Ellis, Basturkmen, \& Loewen, 2001a, Ellis, Basturkmen, \& Loewen, 2001b; Loewen, 2004, 2005; Lyster 1998a, 1998b, 2004; Lyster and Mori, 2006; Lyster and Ranta, 1997 among others).

The term uptake originally comes from speech act theory and describes the relationship between illocutionary and perlocutionary acts (Smith, 2005). However, in SLA literature it is used with a different meaning. Allwright (1984) uses the term to refer to the language items that learners themselves claim to have learned from a particular lesson. Lyster and Ranta (1997) maintain that:

uptake refers to a student's utterance that immediately follows the teacher's feedback to draw attention to some aspect of the student' $s$ initial utterance (this overall intention is clear to the student although the teacher's specific linguistic focus may not be) (p. 49).

Smith (2005) summarizes definitions of uptake presented by Ellis et al. (2001a) as follows:

1. Uptake is student move.

2. The move is optional.

3. The uptake move occurs in episodes where learners have a demonstrated gap in their knowledge.

4. The uptake move occurs as a reaction to some preceding move in which another participant either explicitly or implicitly provides information about a linguistic feature.

Uptake is argued to a) demonstrate a mismatch between the learner utterance and lead to noticing on the learners' part (Lightbown, 1998), b) enhance fluency (Swain, 1995), c) contribute to operationalization of pushed output in classroom setting (Swain, 1985), d) prompt reanalysis and modification of non-target form in the output as the learners test new hypotheses about the target language (Lyster, 1998a), and finally e) serve a predictor of overall performance on tests (Loewen, 2005).

\section{A. Significance of Uptake}

Smith (2005) believes that recent research into the nature and the role of uptake has been twofold, attempting, on the one hand to demonstrate which factors tend to elicit uptake, and, on the other hand, to explore the effectiveness of learner uptake. In Loewen's terms, the recent interest in uptake is due to its potential as an indication of second language acquisition (Loewen 2004). It is argued that there are theoretical grounds for associating uptake with potentials for acquisition. One way in which uptake may facilitate acquisition is by "providing opportunities for learners to proceduralize target language knowledge already internalized in declarative form" (Lyster, 1998a, p. 191). Drawing on processing approaches (to SLA Mc Laughlin, 1987; Mitchell and Myles, 2003), it can be said that learners first 
resort to controlled processing in the second language. Through repeated activation, sequences first produced by controlled processing become automatic. Automatized sequences are stored as units in the long-term memory, which means that they can be made available very rapidly whenever the situation requires it, with minimal attentional control on the part of the subject (Mitchell and Myles 2003, p. 101). Seen from this viewpoint, language learning is the movement from controlled to automatic processing via practice (repeated activation). With these tokens, it can be claimed that learners, by producing the correct form (uptake), shift from controlled processing to automatic processing smoothly and efficiently.

Along these lines, Lightbown (1998, p. 193) suggested that a reformulated utterance from the learner gives some reason to believe that the mismatch between learner utterance and target utterance has been noticed, a step at least toward acquisition. Swain (1985), in the same vein, highlights the role of uptake in operationalizing student-teacher interaction to fortify pushed output, which is a source of hypothesizing and testing about target language on the learners' part.

Ellis et al. (2001b) make a distinction between successful uptake and unsuccessful uptake. Successful uptake was defined as uptake in which learners clearly demonstrated an ability to incorporate the information provided (e.g., by paraphrasing it) or to use the item correctly in their own utterances. Unsuccessful uptake was defined as uptake consisting of just an acknowledgment or a simple repetition of something the teacher had said or of the incorrect use of the item (Ellis et al. 2001b). Although such acknowledgments and repetitions were coded as uptake because they constituted a reaction to the information provided they were coded as unsuccessful because they did not clearly indicate that students had processed the information.

Ellis et al., (2001b) have employed the following categorization for the better study of 'uptake':

- No Uptake; the learner does not produce any uptake where uptake is possible.

- Recognize; the learner acknowledges the information received from the interlocutor in the response phase, using a variety of linguistic tokens including: okay, I see, I got it, aha, all right or mmm. This category also includes those moves where the learner acknowledges the information received in a longer utterance but does not use the target item productively.

- Apply; the learner actually uses the target item productively.

\section{B. Findings on Uptake}

Ellis et al., (2001a) found that uptake occurred in close to $75 \%$ of those focus on form episodes (FFEs) where it was possible. When uptake did occur, it was successful almost $75 \%$ of the time. Uptake was also more likely to occur in episodes involving negotiation of meaning, which in their study included negotiation around vocabulary, and was more common and more successful in complex rather than simple FFEs. Complex episodes, that is to say, involved more than one exchange among interactants, and simple episodes consisted of a single exchange. Moreover, uptake occurred more often and more successfully in FFEs that were responsive in nature (responding to a problematic learner utterance) and in those that were student rather teacher-initiated. Loewen (2004) found that $73 \%$ of all FFEs contained uptake. When uptake occurred, it was successful more than $61 \%$ of the time. In addition to investigating the frequency of uptake, studies also examined factors that might contribute to the production of uptake. For example, Lyster and Ranta (1997) found that elicitation was the most successful in generating uptake $(100 \%)$, followed by clarification requests $(88 \%)$, metalinguistic feedback (86\%), repetition (78\%), and the explicit correction (50\%). Recasts were the least repairs" are more useful, because they involve students in greater amount of processing.

In Loewen (2004), complex FFEs were roughly four and a half times more likely than simple FFEs to produce uptake. He also showed that deferred FFEs were roughly one-fifth as likely to contain uptake as immediate FFEs. And additionally, elicits were three and a half times more likely result in uptake than were provides.

Drawing on earlier research, Smith (2005) suggests that uptake is more likely to occur and be successful in FFEs that (a) involve negotiated interaction, (b) are complex rather than simple in nature, and (c) are student rather than other initiated. Furthermore, uptake should not be viewed exclusively in terms of teacher-student error correction (Ellis et al., 2001a)

\section{Task}

Although a good many studies have concentrated on the process and outcome of uptake, no study has to date addressed the influence of a preceding phenomenon. A typically worthwhile issue to examine can be task. Task as a meaning-focused activity or set of activities is supposed to ensure language learner involvement in communicating meaning, which is likely to lead to implicit (i.e. natural) learning (see Crabbe, 2007). The great advantage of task, as Widdowson (2003) puts it, is providing opportunities for learner engagement in realizing the communicative potential of the encoded semantic resource.

Interestingly enough, the same cognitive orientation that informs uptake seems to underlie a substantial segment of studies in task research. Cognitive approach to task primarily concentrates on limited short-term memory capacity, which imposes processing burden on the learners' attentional resources (Ellis, 2005). The factors that trigger these processing demands are believed to lead to 'task complexity' (see Robinson, 2001a for example). Robinson's Cognition Hypothesis $(2001$ b , 2003, 2005, 2007) claims that increasing the cognitive demands (through increasing the cognitive complexity) of tasks along certain dimensions will; (a) push learners to greater accuracy and complexity of L2 
production in order to meet the greater functional and conceptual communicative demands they place on the learner; (b) promote interaction, and heightened attention to and memory for input, so increasing learning from the input; as well as (c) longer term retention of input; and that (d) performing simple to complex sequences will also lead to automaticity and efficient scheduling of the components of complex L2 task performance. Robinson (2003, 2005) hypothesized that more interaction and uptake will result from complex performance that complex tasks will perceived as more difficult, stressful and learners will show less confidence in performing that. Robinson (2007b, p. 193), also, found that tasks requiring complex reasoning about character's intentional states led to significantly more interaction.

The Cognition Hypothesis also connects input and interaction to the cognitive and conceptual demands of tasks that lead to differential amounts of interaction, or uptake of forms made salient in the input to tasks (Robinson, 2007 b). Following Long (1996), the Cognition Hypothesis claims that such negotiation provides a context for attending to problematic forms in the input and output, and additionally that on complex versions of tasks will require greater attention to, and uptake of forms made salient during provision of reactive focus on Form techniques such as recasts (see Long, 2007).

Robinson (2007b) demonstrated that measures of uptake partial and uptake per turn differ significantly across task versions. He came up with significantly more uptake on complex versus simple versions. That is to say, Robinson (2007b), operationalized uptake as use of premodified input provided proactively in the materials used to support task performance. The present study, moreover, seeks to fill the gap in the literature felt by Robinson (2007b) that "no study to date has examined the effects of task complexity on uptake". Moreover, given the acquisitional potential of 'uptake' that may be facilitative of language acquisition (Ellis et al., 2001b, Loewen, 2004); it seems promising to investigate learner uptake during performing complex tasks vs. simpler ones. Attaching acquisitional value to learner uptake means that more learner uptake may be concomitant to more opportunities for 'noticing' (Loewen, 2004), and more language acquisition opportunities (Robinson, 2007b).

\section{Task Complexity in the Scope of the Present Study}

Elaborating on dimension of task complexity would be well outside the scope of the present paper. This being the case, and also for the purpose of singling out complex tasks as variables in this study, the authors have concentrated on the notion of 'interconnectedness' as an instance of cognitive complexity.

Interconnectedness, as the name suggests, can be described as the state in which elements in a task are not clearly separated, but rather involve a connection or overlap. Gilabert (2007) relates the complexity of language produced by learners to increases in task demands assigning them to the manifestations of interconnectedness: specifying referential location, referring to a set of similar landmarks, and direction towards the goal and perspective along different axes, and higher degree of similarity.

According to Robinson (2001b) tasks that involve clearly distinguishable elements “. . . . are simpler than tasks which require many similar elements to be distinguished from each other (e. g., cars in a traffic jam, buildings and streets on a map, or suspects in a police line-up)" (pp. 312-3).

Skehan (1998b), though quite implicitly, raises the issue of interconnectedness as a predictor of difficulty (which is of course equivalent for complexity in his own terms):

...more elements or characters make for greater task difficulty. Also important, but less developed, is the idea that the nature of the relationship between the elements contributes separately to task difficulty. This suggests that different sorts of relationship may lead to different degrees of difficulty (p. 103)

The Cognition Hypothesis (Robinson, 2001a, 2001b, 2005a) suggests that reference to few easily distinguished elements is easier than reference to many similar elements or interconnected ones. It can be claimed that the higher the similarity among the elements of a task, the more complex will be the task. In the same vein, Evans and Marciniak (1987) suggested that complexity is related to the intricacy of systems, the higher the number of factors and relations within a system, and the higher the amount of element interactivity, the more complex this system is.

With this background in mind the present study seeks to answer the following research questions:

\section{RESEARCH QUESTIONS}

R. Q. 1. Does task complexity influence the rate of uptake in task-elicited oral performance in L2?

R. Q. 2. Does complexity of the task significantly determine the frequency of successful uptakes in the elicited performance?

\section{METHOD}

\section{A. Participants}

Participants were 60 volunteer Iranian male EFL learners, aged between 17 and 25 (mean= 20) who had been in lower intermediate level of oral proficiency in English. The participants included 38 learners from a private language institute in Miandoab, Iran. Their cohorts were from Jihad Daneshgahi Language institute in Urumia (22 male learners). Based on the levels of the courses they had enrolled in and on the results of their in-house language placement tests (including written and oral interview tests), the participants were considered as homogeneous. They could also pass two 
immediate last terms with an average of over 85 out of 100. Before participating in the research, the participants (in both sites) had received English education for approximately five years. They had also passed two immediate with an average of over 85 out of 100 in the earlier semester. The participants were from different L1 backgrounds, including Turkish, Persian, and Kurdish. Deliberate attempts have been made to select participants randomly and avoid any bias towards any group of the learners. The selection procedure was done according to the student number allocated to each student through drawing lots procedure. All the participants in this study expressed their satisfaction prior to the research and they were told that the result would not have any effect on the students' grades in the courses they were taking.

\section{B. Materials}

Two versions of the same decision-making task (one simple and another complex task) were replicated from Gilabert (2007). A simplified 'fire chief' task used in cognitive psychology was utilized. In this task, (see the appendix) learners were presented with a building where a fire had broken out and a number of people needed to be rescued. The problem in the complex version required the learners not just one decision, but a long series of decisions, in which early decisions lead to later ones. In both versions of the task learners were instructed to specify the actions they would take, determine the sequence of their actions, and justify their choice for actions and specific sequences of the actions they would like to do. In the simple task, there were similar types of people (i.e. people with no particular roles) in the building who were encountered with similar degrees of danger; the fire being relatively static, the smoke blowing away from the building and the learners had many resources (three fire trucks and a helicopter). In the complex one, learners had to deal with people who had specific roles (e.g. a pregnant woman, an elderly man, an injured person, a hero). The factors in the complex task were also intricately related and dynamic (e.g. the different fires moving towards the people and the smoke blowing into building through the ventilation system) and they had fewer resources (i.e. a single fire truck), which is thought would force learners to prioritize, and later justify their actions (Gilabert, 2007). The dimension of task complexity addressed was increases in reasoning demands (complex task has more reasoning demands than the simple one).

As pointed out by Robinson and Gilabert (2007), task complexity, in this task, was enhanced through interconnectedness. Since interconnectedness among the variables present in a task contributes to its complexity and places heavy burden on the learner attentional and reasoning as well as short- term memory capacities.

\section{Procedure}

Data collection took place in a quiet room in each language institute. It was done in a dyadic condition. Nobody other than the first researcher and each participant were present. Apart from age and first language background, no personal information was obtained. After collecting personal information and achieving rapport with the participants, they were told of the demands of the task at hand. The participants were provided with one or two words (e. g, fire truck) which had found to be problematic during pilot study.

The participants did the simple and complex tasks consecutively with a 30-minute time gap. The participants were given one minute prior to task performance to think how to do the required task. They were allocated up to seven minutes to perform the specified task.

The participants, looking at the tasks, transacted the tasks and if they came up with a linguistic error, they have been provided by the corrective feedback (e. g. recast) to correct their erroneous utterances. Their responses to the researcher's corrective feedback were either successful uptake or unsuccessful uptake. In some cases, researcher's corrective feedback went unnoticed on the part of the participants (hence No Uptake). It should be mentioned that the whole procedure of the data collection was audiotaped.

Uptake, in this study, was studied through identifying the Focus on Form Episodes (FFES) within the interactions (as done by Loewen, 2004). An FFE was defined as consisting of " the discourse from the point where the attention to linguistic form starts to the point where it ends, due to a change in topic back to message or sometimes another focus on form (Ellis et al., 2001a). After identifying FFES, the uptake moves were classified according to the classification has used by (Ellis et al., 2001a) was employed.

As stated earlier, uptake was operationalized as learners' responses to the teacher corrective feedback on a linguistic item. These responses make take several states: a. Successful Uptake; in which learners demonstrated an ability to incorporate the information provided or to use item correctly in their utterances (Ellis et al., 2001a):

$\mathrm{S}$ : in third level.

T: third floor?

S: yeah, third floor. (This extract has been taken from the present study).

Unsuccessful Uptake was defined as uptake consisting of just an acknowledgement or simple repetition of something the teacher has said or of the incorrect use of the item (Ellis et al, 2001a);

$\mathrm{S}$ : he need to be help.

T: needs to be helped.

S: yeah, he needs to help. (This extract has been taken from the present study) 
In this FFE, the researcher responded to the learner's erroneous utterance through corrective feedback. Having noticed the feedback, the learner incorporated part of the linguistic items into his own output (NEEDS), at the same time he failed to incorporate (TO BE HELPED) into his production (hence, Unsuccessful Uptake).

Ellis et al., 2001a pointed out, operationally, this consisted of uptake coded as Acknowledge, Needs repair, Recognize, or Needs application. No Uptake category means learner does not respond to the teacher's corrective feedback.

For the purpose of data analysis, successful and unsuccessful uptakes were added; because unsuccessful uptake is considered as learner's attempt to be more accurate. This is exactly the point asserted by Loewen (2004).

No Uptake category means that the learner has not responded to the corrective feedback of the teacher:

$\mathrm{S}$ : I think best way is that....

$\mathrm{T}$ : The best way?

$\mathrm{S}$ : No response

In this situation the learner continues to his own production and pays no attention to the corrective feedback of the teacher.

\section{Data Collection}

The gathered data were organized into two figures. The first figure contained the data on the rate of uptake. In other words, uptake as opposed to no-uptake outcomes (quantified through Frequency of Focus on Form Episodes) across simple and complex tasks were presented (see Figure 1 below). The second table further distinguished the uptake into successful vs. unsuccessful uptakes in simple vs. complex task situations (see Table 2).

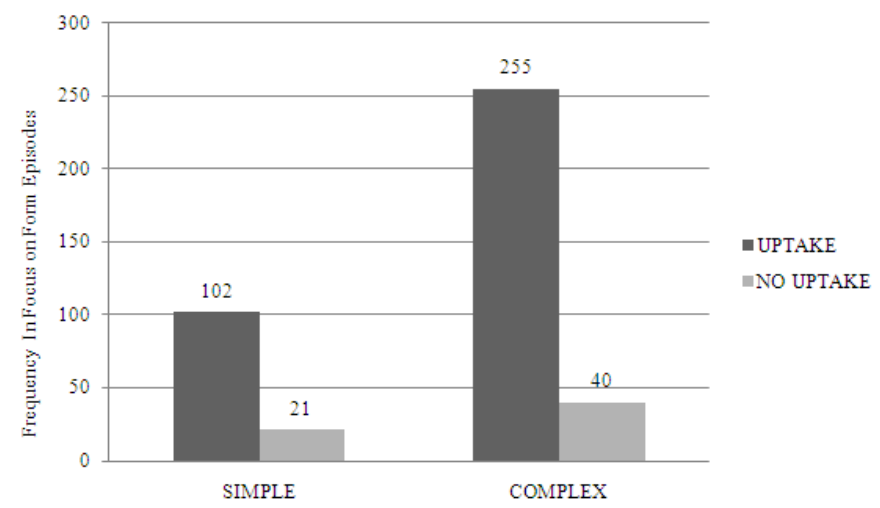

Figure 1. Uptake vs. no uptake outcomes in simple vs. complex task situations in terms of the frequency of FFEs (Focus on Form Episodes)

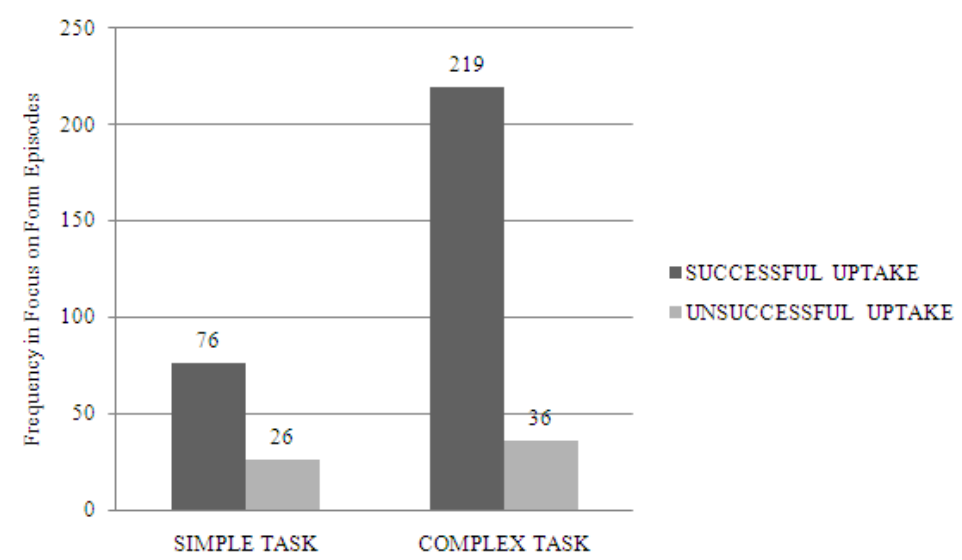

Figure 2. Successful vs. unsuccessful uptakes in simple vs. complex tasks situations in terms of the frequency of FFEs (Focus on Form Episodes).

\section{E. Data Analysis}

Since the type of the data collected was frequency, for each of the two research questions a $2 \times 2$ Chi-square test was employed for hypothesis testing using SPSS 17: For research question one, the Chi-square value turned out to be 0.86 which was not significant at $\mathrm{p}<0.05$. See Table 1 below.

TABLE 1.

CHI-SQUARE RESULTS FOR UPTAKE VS NO-UPTAKE ACROSS SIMPLE AND COMPLEX TASK PERFORMANCES.

\begin{tabular}{|c|c|c|c|}
\hline & value & df & Significance \\
\hline Chi-square & 0.86 & 1 & 0.35 \\
\hline
\end{tabular}


For research question two, the Chi-square value was 6.56, large enough in value to reject the null hypothesis. See Table 2 below.

TABLE 2.

CHI-SQUARE RESULTS FOR SUCCESSFUL VS. UNSUCCESSFUL UPTAKES ACROSS SIMPLE AND COMPLEX PERFORMANCES

\begin{tabular}{|c|c|c|c|}
\hline & value & $\mathrm{df}$ & Significance \\
\hline Chi-square & 6.55 & 1 & $0.01 *$ \\
\hline
\end{tabular}

Significant differences obtained for successful vs. unsuccessful uptakes across simple and complex tasks suggest that successful uptake occurred with a higher frequency in complex task than in simple task.

\section{DISCUSSION \& CONCLUSION}

For research question 1 "Does task complexity influence the rate of uptake in task-elicited oral performance in L2?" the statistical analysis indicated the rate of uptake was not determined by task complexity. This is contradicted by Ellis et al (2001 a), Loewen (2004) Smith (2005) and Robinson (2007) who support a high rate of uptake for FFEs. The finding as such, at least on the scale of this study, suggests that interaction as a process is dynamic, complicated and unpredictable. The increase in cognitive demands of the task due to the influence of the complex task could not prompt the learners to produce utterances following the teachers' feedback. Therefore, as far as the learner is concerned, feedback on the teacher's part is no guarantee that uptake will occur. The fact that the rate of uptake can be independent of the complexity of the task might mean that production of uptake can be a matter of task-specific requirements, developmental readiness of the learners or even affective factors. Also, it must be noted that variations in terms of context may have their impact on the rate of uptake in task-elicited form-focused interaction.

Concerning research question 2, "Does complexity of the task significantly determine the frequency of successful uptakes in the elicited performance?" the statistical analysis revealed a significantly high frequency of successful uptake for complex task than for simple task. This finding is supported by Ellis et al (2001 a), Loewen (2004) Smith (2005) and Robinson (2007c) who reported that most uptakes were successful. There are no refuting results in this regard. Drawing on Lyster (1998b), it can be claimed that learners in the study show signs of moving from controlled to automatic processing through producing successful uptakes. Also, following Ellis et al. (2001) learners were shown to possess either the ability to incorporate the information provided in the FFEs or to employ the language item accurately in their task-elicited speech.

To put together the answers to the two research questions, it can be claimed that within the scope of the present study, task complexity did not significantly affect the rate of uptake, but it did determine the frequency of successful uptake.

Studying the relationship between uptake and task can be very enlightening in several ways. First, uptake can be a criterion against which differential degrees of noticing during and after task performance can be gauged. In this way, cognitive capacity of the learners for task performance can be ensured which is yet another yardstick for grading and sequencing tasks. Further research can examine the hypothetical claim that the automatized processing represented by correct form production (uptake) (Mitchell and Myles, 2003), can free the learners' attentional resources to attend to fluency, with the latter being one of the core commitments of task-based instructional approaches. Another way in which task and uptake can mutually benefit is to incorporate uptake in the psycholinguistic approach to task, which lays emphasis on the role of interaction and the way it can contribute to negotiation of meaning (Gass 2002; Mackey, Gass, and McDonough, 2000). Findings on uptake can also bear potentials for socio-cultural approach to task-elicited interaction. Within this approach learning is viewed a social action subject to the learners' collaborative co-construction (Lantolf, 2000; Duff, 1993; Coughlan and Duff, 1994; Swain and Lapkin, 2001; Van Lier and Matsu, 2000, Nakahama, Tyler \& Van Lier, 2001; Skehan, 2003). 


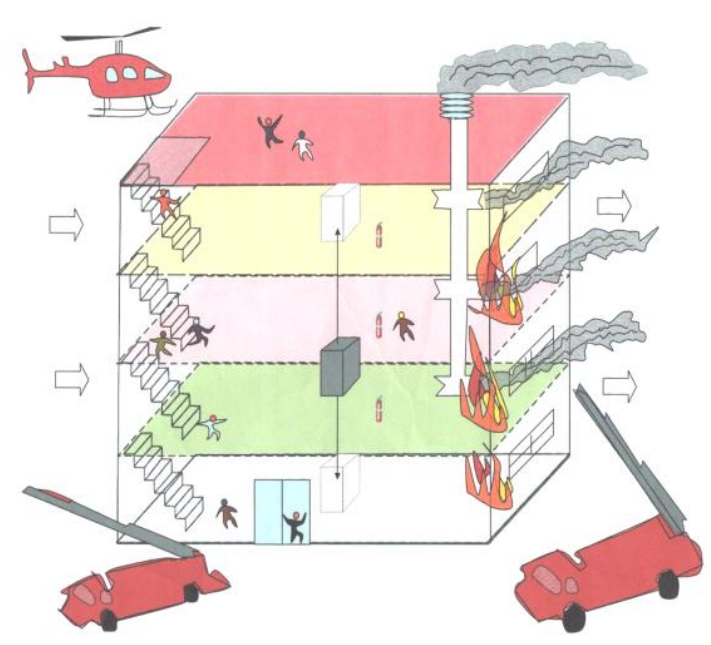

APPENDIX 2: COMPLEX TASKS

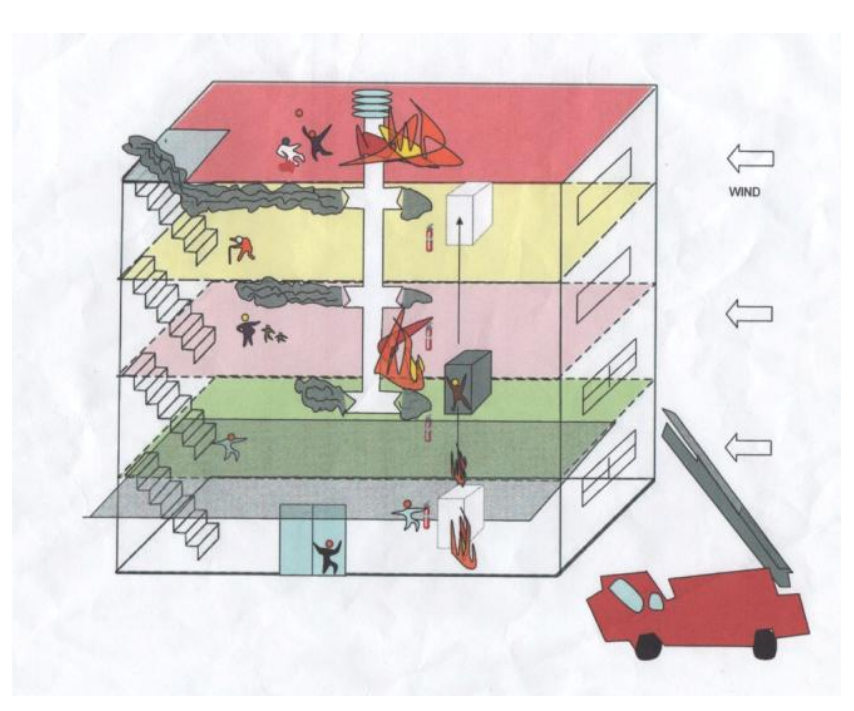

\section{REFERENCES}

[1] Allwright, D. (1984). Why don't learners learn what the teachers teach? The interaction hypothesis. In D. Singleton and D. Little (Eds.). Language learning in formal and informal contexts (pp.3-18). Dublin. IRAAL.

[2] Coughlan, P. and P. Duff. (1994). Same task different activities: Analysis of a second language acquisition task from an activity theory perspective. In J. Lantolf and G. Appel (Eds.) Vygotsky approaches to second language research. Norwood, N. J.: Ablex.

[3] Crabbe, D. (2007). Learning opportunities: Adding learning value to tasks. ELT Journal, 61, 117-125.

[4] Crooks, G. (1989). Planning and interlanguage variation, Studies in Second Language Acquisition, 11, $367-383$.

[5] Duff, P. (1993). Tasks and interlanguage performance: An SLA perspective. In G. Crookes and S. Gass (Eds.) Tasks and language learning: Integrating theory and practice. Clevedon, Avon: Multilingual Matters.

[6] Ellis, R (Ed.) (2005). Planning and task performance in a second language. Amsterdam: John Benjamins.

[7] Ellis, R. \& Barkhuizen, G. (2005). Analyzing learner language. Oxford: Oxford University Press.

[8] Ellis, R. (1993). Second language acquisition and the structural syllabuses. TESOL Quarterly, 27, 91-113.

[9] Ellis, R. (1994). The study of second language acquisition. Oxford: Oxford University Press.

[10] Ellis, R. (2003). Task-based language learning and teaching. Oxford: Oxford University Press.

[11] Ellis, R., Basturkmen, H., \& Loewen, S. (2001a). Learner uptake in communicative ESL lessons. Language Learning, 51, 281326.

[12] Ellis, R., Basturkmen, H., \& Loewen, S. (2001b). Preemptive focus on form in ESL classroom. TESOEL Quarterly, 34, 407432.

[13] Evans, M. W., \& Marciniak, J. (1987). Software quality assurance and management. New York, USA: John Wiley \& Sons.

[14] Foster, P. (1999). Task-based learning and pedagogy. ELT Journal, 53, 69-70. 
[15] Foster, P., \& Skehan, P. (1996). The influence of planning and task type on second language performance. Studies in Second Language Acquisition, 9, 12-20.

[16] Foster, P., \& Skehan, P. (1999). The influence of planning and focus of planning on task-based performance. Language Teaching Research, 3, 215-247.

[17] Gass, S. (1998). Integrating research areas: A framework for second language studies. Applied Linguistics, 9, 198-217.

[18] Gass, S. (2002). Interactionsit perspectives in Second Language Acquisition. In R. Kaplan (Ed.), Handbook of applied linguistics (pp.170-181). Oxford. Oxford University Press.

[19] Gilabert, R. (2007). Effects of manipulating task complexity on self-repair during L2 oral production. IRAL, 45, 215-240.

[20] Givon, T. (1989). Mind, code, and context: Essays in pragmatics. Hillsdale, NJ: Erlbaum.

[21] Hardy, I., \& Moore, J. (2004). Foreign language student's conversational negotiations in different task environments. Applied Linguistics, 25, 340-370.

[22] Kumaravadivelu, B. (2006). TESOL methods: Changing tracks, challenging trends. TESOL Quarterly, 40, 59-81.

[23] Lantolf, J. (2000). Sociocultural theory and second language learning. Oxford: Oxford University Press.

[24] Lightbown, P. (1998). The importance of timing in focus on form. In C. Doughty \& J.Williams (Eds.), Focus on form in classroom second language acquisition (pp. 177-196). Cambridge: Cambridge University Press. Linguistics.11: 17-46.

[25] Loewen, S. (2004). Uptake in incidental focus on form in meaning-focused ESL lessons. Language Learning, 54, 153-188.

[26] Loewen, S. (2005). Incidental focus on form and second language acquisition. Studies in Second Language Acquisition, 26, 361-386.

[27] Long, M. (Ed.) (2007). Problems in SLA. Mahwah, NJ: Erlbaum.

[28] Long, M. H. (1996). The role of linguistic environment in second language acquisition. In W. C. Ritchie\& T.K. Bhatia (Eds.). Handbook of second language acquisition. (pp. 413-463). San Diego: Academic Press.

[29] Lyster, R. (1998a). Negotiation of form, recasts, and explicit correction in relation to error types and learner repair in immersion classrooms. Language Learning, 48, 183-218.

[30] Lyster, R. (1998b). Recasts, repetition, and ambiguity in L2 classroom discourse. Studies in Second Language Acquisition, 20, 51-81.

[31] Lyster, R. (2004). Differential effects of prompts and recasts in form-focused instruction. Studies in Second Language Acquisition, 26, 399-432.

[32] Lyster, R., \& Mori, H. (2006). Interactional feedback and instructional counterbalance Studies in Second Language Studies, 28, 269-300.

[33] Lyster, R., \& Ranta, L. (1997). Corrective feedback and learner uptake: Negotiation of form in communicative classrooms. Studies in Second Language Acquisition, 19, 37-66.

[34] Mackey, A., S. Gass, and K. McDonough. (2000). Do learners recognize implicit negative feedback as feedback? Studies in Second Language Acquisition, 22, 471-97.

[35] McLaughlin, B. (1987). Theories of second language learning. London: Edward Arnold.

[36] Mitchell, R., \& Myles, F. (2003). Second language learning theories. London: Hodder. Arnold.

[37] Mortazanejad, S. (2008). L2 learner performance in planned vs. unplanned condition. Unpublished M.A. dissertation. University of Tabriz, Iran.

[38] Nakahama, Y., A. Tyler and L. Van Lier. (2001). Negotiation of meaning in conversational and information gap activities: A comparative discourse analysis. TESOL Quarterly, 35, 377-405.

[39] Robinson, P. (1995a). Task complexity and second language narrative discourse, Language Learning, 45, 99-140.

[40] Robinson, P. (1995b). Attention, memory and the "noticing" hypothesis. Language Learning, 45, 283-331.

[41] Robinson, P. (1996). Task complexity and second language syllabus design: data-based studies and speculations. Working papers in language and linguistics, 1, 1-15.

[42] Robinson, P. (1998). State of the art: SLA theory and second language syllabus design. The Language Teacher, 22, 7-14.

[43] Robinson, P. (2001a). Task complexity, task difficulty, and task production: exploring interactions in a componential framework. Applied Linguistics, 22, 27-57.

[44] Robinson, P. (2001b). Task complexity, cognitive resources, and syllabus design: A triadic framework for examining task influences on SLA. In P. Robinson (Ed.), Cognition and second language instruction (pp.285-316). Cambridge: Cambridge University Press.

[45] Robinson, P. (2003b). The cognition hypothesis, task design, and adult task-based language learning. Second Language Studies, 21, 45-105.

[46] Robinson, P. (2005a). Cognitive complexity and task sequencing: A review of studies in a componential framework for second language task design. International Review of Applied Linguistics in Language Teaching, 43(1), 1-33.

[47] Robinson, P. (2007a). Criteria for grading and sequencing pedagogic tasks. In Maria Del Pilar Garcia Mayo (Ed.), investigating tasks in formal language learning, (pp.2-27). Clevedon: Multilingual Matters.

[48] Robinson, P. (2007c). Task complexity, theory of mind, and intentional reasoning: Effects on L2 speech production, interaction, uptake and perceptions of task difficulty. IRAL, 193-213.

[49] Robinson, P., \& Gilabert, R. (2007). Task complexity, the Cognition Hypothesis and second language learning and performance. IRAL 45, 161-176.

[50] Skehan, P. (1996). A framework for the implementation of task-based instruction. Applied Linguistics, 17, 38-62.

[51] Skehan, P. (1998a). Task-based instruction. Annual Review of Applied Linguistics, 18, 268-286.

[52] Skehan, P. (1998b). A cognitive approach to language learning. Oxford: Oxford University Press.

[53] Skehan, P. (2002). A non-marginal role for task. ELT Journal, 563, 289-295.

[54] Skehan, P. (2003a). Focus on form, tasks, and technology. Computer Assisted Language Learning, 16, 391-411.

[55] Skehan, P. (2003b). Task-based instruction, Language Teaching, 36, 1-14.

[56] Skehan, P., \& Foster, P. (1997). Task type and task processing conditions as influences on foreign language performance. Language Teaching Research, 1, 1-27. 
[57] Skehan, P., \& Foster, P. (2001).Cognition and tasks. In P. Robinson (Ed.) Cognition and second language instruction, (pp.183205). Cambridge: Cambridge University Press.

[58] Smith, B. (2005). The relationship between negotiated Interactions, learner uptake, and lexical acquisition in task-based computer mediated communication. TESOL Quarterly, 39(1), 33-58.

[59] Swain, M. (1985). Communicative competence: Some roles of comprehensive input and comprehensive output in its development in S. Gass and C. Madden (Eds.), Input in Second language acquisition (pp.235-253). Rowley, MA: Newbury House.

[60] Swain, M. (1995). Three functions of output in second language. In H.G. Widdowson, G.Cook \& B. Seidlhofer (Eds.), Principles and practice in applied linguistics: Studies in honor of H. G. Widdowson (pp.125-144). Oxford: Oxford University Press.

[61] Swain, M. (2000). The output hypothesis and beyond: Mediating acquisition through collaborative dialogue. In J. Lantolf (Ed.), Sociocultural theory and second language learning (pp. 97-114). Oxford: Oxford University Press.

[62] Swain, M., and S. Lapkin. (2001). Focus on form through collaborative dialogue: Exploring task effects. In M. Bygate, P. Skehan, and M. Swain. (Eds.) Researching pedagogic tasks: Second language learning, teaching and testing. London: Longman.

[63] Van Lier, L. and N. Matsu. (2000). Varieties of conversational experience: Looking for learning opportunities. Applied Language Learning, 11, 256-87.

[64] Van Patten, B. (2004). Input processing in SLA. In B. Van Patten (Ed.), Processing instruction theory, research, and commentary (pp.5-31). Mahwah, NJ: Lawrence Erlbaum.

[65] VanPatten, b. (1990). Attending to form and content in the input. Studies in Second Language Acquisition, 12, $287-301$.

[66] Widdowson, H. G. (2003). Defining issues in English language teaching. Oxford: Oxford University Press.

Massoud Yaghoubi-Notash is an assistant professor of ELT, at the Department of English, University of Tabriz, Iran. He has presented several papers in International conferences and presented co-authored papers on task-related themes and issues. His areas of interest include task-based language teaching and learning, gender, and discourse.

Mohammad Hossein Yousefi holds an MA degree in ELT from University of Tabriz. He is currently a full-time high school teacher of English in Miandoab, and teaches undergraduate (BA) English translation majors at the local Payamenoor University. His areas of interest are uptake, form-focused instruction, and task-based language teaching and learning. 